Kansas State University Libraries

New Prairie Press

Conference on Applied Statistics in Agriculture

1993 - 5th Annual Conference Proceedings

\title{
ANALYSIS OF SPATIAL VARIABILITY USING PROC MIXED
}

David B. Marx

Walter W. Stroup

Follow this and additional works at: https://newprairiepress.org/agstatconference

Part of the Agriculture Commons, and the Applied Statistics Commons

\section{(c) $($ () $\ominus$}

This work is licensed under a Creative Commons Attribution-Noncommercial-No Derivative Works 4.0 License.

\section{Recommended Citation}

Marx, David B. and Stroup, Walter W. (1993). "ANALYSIS OF SPATIAL VARIABILITY USING PROC MIXED," Conference on Applied Statistics in Agriculture. https://doi.org/10.4148/2475-7772.1371

This is brought to you for free and open access by the Conferences at New Prairie Press. It has been accepted for inclusion in Conference on Applied Statistics in Agriculture by an authorized administrator of New Prairie Press. For more information, please contact cads@k-state.edu. 
ANALYSIS OF SPATIAL VARIABILITY USING PROC MIXED

\author{
David B. Marx and Walter W. Stroup \\ Department of Biometry \\ University of Nebraska-Lincoln \\ Lincoln, NE 68583-0712
}

\begin{abstract}
Many data sets in agricultural research have spatially correlated observations. Examples include field trials conducted on heterogeneous plots for which blocking is inadequate, soil fertility surveys, ground water resource research, etc. Such data sets may be intended for treatment comparisons or for characterization. In either case, linear models with correlated errors are typically used. Geostatistical models such as those used in "kriging" are often used to estimate the error structure.
\end{abstract}

SAS PROC MIXED allows the estimation of the parameters of mixed linear models with correlated errors. Fixed and random effects are estimated by generalized least squares. Variance and covariance components are estimated by restricted maximum likelihood (REML).

The purpose of this presentation is to show how PROC MIXED can be used to work with spatial data. Several examples will be presented to illustrate how various analyses could be approached and some of the pitfalls users may encounter.

\title{
1. INTRODUCTION
}

Statistical methods traditionally used in agricultural research have emphasized designs and analyses which assume that variation among experimental units is either (i) homogeneous or (ii) can be controlled by blocking. In many field situations, however, variation is more likely to be characterized by smooth, localized, irregular trends - variation which is neither homogeneous nor necessarily well-controlled by blocking.

Figure 1 illustrates the distinction among these three general classes of variability. Rows and columns represent field plots in a rectangular arrangement and the $y$-variable is some response of interest. The first case represents variation across the field when we have "homogeneous" experimental units, the nominal situation for which the completely random design its associated analysis of variance are appropriate. These data were produced by a normal random number generator. The second case represents experimental units with obvious homogeneous subsets - an idealized case for the use of a blocked design and its associated analysis of variance. The third case is a visual characterization of spatial variability - the variation obviously has pattern, but the pattern, while smooth, is irregular and an implementable criterion for blocking is not obvious.

In the third case, the pattern of variability can often be characterized by a linear model with spatially correlated errors. Mixed linear model methods (Henderson, 1975; Harville, 1976, 1977; McLean, Sanders, and Stroup, 1991) are therefore useful tools to analyze such data.

The general form of the mixed linear model is as follows.

$$
\mathbf{Y}=X \boldsymbol{X}+\mathrm{Zu}+\mathbf{e},
$$

where $\quad y$ is a vector of observations;

$\mathrm{X}$ is a matrix of constants (describing regression or design structure) for the fixed effects; 


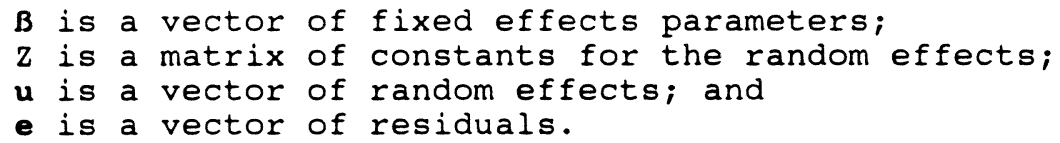

For the random effects, $\mathbf{u}$ and $\mathbf{e}$, assume $E(\mathbf{u})=E(\mathbf{e})=0, \operatorname{Var}(\mathbf{u})=G, \operatorname{Var}(\mathbf{e})$ $=R$, and $\operatorname{Cov}\left(\mathbf{u}, \mathbf{e}^{\prime}\right)=0$. In "traditional" models, e.g. standard analysis of variance models for completely random and randomized block designs, $R=I \sigma^{2}$ is assumed, but mixed model theory places no requirements on $R$ or $G$ - both can be general.

Inference with mixed linear model has three basic building blocks. The first is the mixed model equation, used to estimate $B$ and $u$, given as follows :

$$
\left[\begin{array}{ll}
X \cdot R^{-1} X & X^{\prime} R^{-1} Z \\
Z^{\prime} R^{-1} X & Z^{\prime} R^{-1} Z+G^{-1}
\end{array}\right]\left[\begin{array}{l}
B \\
u
\end{array}\right]=\left[\begin{array}{c}
X^{\prime} R^{-1} Y \\
Z^{\prime} R^{-1} Y
\end{array}\right]
$$

In most cases, the variance and covariance components of $G$ and $R$ are unknown, and estimates must be used. Estimates are typically obtained using restricted maximum likelihood (REML), although other methods can be used.

The second building block of inference is the predictable function, $\mathrm{K}$ ' $\mathrm{B}$ $+M^{\prime} u$, which is predictable is $K^{\prime} B$ is estimable. Adjusted marginal treatment means (a.k.a. "Least squares means"), treatment differences, and contrasts are typical predictable functions of interest to researchers. The marginal means or treatment comparisons of interest guide the choice of $K$. In most applications, $M$ will be a matrix of zeros, corresponding to what McLean, et. al. (1991) call the "broad inference space." other $M$ matrices may be selected to restrict the inference space or to obtain best linear unbiased predictors (BLUP). See McLean, et. al. (1991) for further detail.

The third building block of interest is the "standard error," or, more precisely, the square root of the prediction error of the estimated predictable function. The standard error is given by the formula $\sqrt{L}$ 'CL, where $L^{\prime}=\left[K^{\prime} M^{\prime}\right]$ and $C$ is the generalized inverse of

$$
\left[\begin{array}{ll}
X \cdot R^{-1} X & X \cdot R^{-1} Z \\
Z \cdot R^{-1} X & Z \cdot R^{-1} Z+G^{-1}
\end{array}\right]
$$

When $L$ is a vector - e.g. when a single marginal mean, treatment contrast, or BLUP is of interest - the ratio estimate/(standard error) is a $t$ statistic and be used as such. In the more general case, where $L$ is a matrix - e.g. when multiple degree of freedom hypotheses, such $\mathrm{H}_{0}$ : all treatment effects equal, are of interest,

$$
\theta^{\prime} L\left(L^{\prime} C L\right)^{-1} L^{\prime} \theta / \operatorname{rank}(L) \text {, where } \theta^{\prime}=\left[B^{\prime} \mathbf{u}^{\prime}\right]
$$

is an approximate F-statistic. The numerator degrees of freedom equal rank(L). The denominator degrees of freedom are more complicated. A naive approach is to use the degrees of freedom implied by the appropriate error term in a analysis of variance table. In more complex models, e.g. for which the implied error from the ANOVA term involves more than one mean square, or the errors are correlated, Satterthwaite's approximation, or other alternatives, may be used. Jeske and Harville (1988) consider this issue in some detail, and the interested reader is referred to their article. PROC 
MIXED (SAS Institute, 1992) uses the naive, ANOVA-analog approach to determine error degrees of freedom.

Several spatial correlation models are potentially useful for agricultural data. Typically, spatial correlation refers to variability among experimental units in a single location (e.g. among plots in a field) and is thus modeled through the covariance of the residual vector, e, that is, the matrix R. Zimmerman and Harville (1991) discuss several alternative structures for R. Many of these were originally developed for applications in geostatistics (Journel \& Huijbregts, 1978). The basic idea is as follows.

In a typical field trial with spatial variability, responses of plots close together are highly correlated, whereas plots farther apart are less correlated. At some critical distance, responses of plots that distance or farther apart are essentially uncorrelated. In geostatistics, the semivariogram is used to characterize spatial variability. The semivariance defined as

$\Gamma(h)=\frac{1}{2} \operatorname{Var}($ difference between pairs of observations $h$ units apart)

The semivariogram is a plot of $\Gamma(h)$ versus $h$. A typical semivariogram is given in Figure 2, below. The key features of the semivariogram are the range, defined as the critical distance above which observations are uncorrelated, the sill, the semivariance of uncorrelated observations (equal to the error variance, it can be shown), and the nugget, defined as the semivariance at distance zero. The nugget describes abrupt changes and was originally intended to model data from searches for diamonds, where probes a very short distance apart could find either nothing or a very high concentration of diamonds. Such abrupt variation is uncommon in agricultural field trials, so the nugget is frequently assumed to be zero. follows :

The semivariance is related to the $R$ matrix in the mixed model as

$\operatorname{Cov}(2$ observations $h$ units apart $)=C(h)=C(0)-\Gamma(h)$.

Thus, $C(0)$ corresponds to the diagonal elements of $R$ and the $C(h)$, where $h>0$, are the off-diagonal elements of $R$. Typical semivariance models for the mixed model are

Spherical

$$
\begin{aligned}
C(h) & =\sigma^{2}\left[1-(3 h / 2 r)+\left(h^{3} / 2 r^{3}\right)\right], & & \text { if } h<r \\
& =0, & & \text { otherwise }
\end{aligned}
$$

Exponential

$$
C(h)=\sigma^{2}[\exp (-h / r)]
$$

Gaussian

$$
C(h)=\sigma^{2}\left[\exp \left(-h^{2} / r^{2}\right)\right]
$$

Linear

$$
\begin{aligned}
C(h) & =\sigma^{2}[1-h r], & & \text { if } h<2 / r \\
& =0, & & \text { otherwise }
\end{aligned}
$$

For all of the above models, two parameters, $\sigma^{2}$ and $r$, corresponding to the error variance and range, respectively, must be estimated.

Each of the above semivariance models describes a different pattern of 
correlation among neighboring experimental units. In the examples given in sections 3 and 4 , we will show how the problem of selecting an appropriate semivariance can be approached. The important concept to keep in mind is that the use of linear models with correlated errors to analyze field data is strongly indicated when irregular, local gradients, as portrayed in Figure 1, case 3, are present. The correlation model is basically a model of the "surface" resulting from such variability.

PROC MIXED (SAS Institute, 1992) permits the user to specify mixed models whose errors are correlated. Error correlation models include all of the semivariance models given above (spherical, gaussian, exponential, and linear) as well as other correlation models not as commonly of interest in agricultural field trials. B and $\mathbf{u}$ are estimated using the mixed model equations [2], and $\sigma^{2}$ and $r$ are estimated using REML. In the following sections, we will present examples of basic applications of mixed models with spatial correlation. We will present the basic PROC MIXED programming requirements, highlights of the output of particular interest, and our experiences with problems and pitfalls users should anticipate.

\section{BASIC PROC MIXED PROGRAMMING AND OUTPUT}

Consider the simplest mixed model with spatially correlated errors,

$$
y_{i j}=\mu+f_{i}+r_{j}+e_{i j},
$$

where $\mu$ and the $f_{i}^{\prime}$ s are fixed, the vector $u$ of $r_{j}$ 's is distributed $N\left(0, I \sigma_{R}{ }^{2}\right)$, and the vector $e$ of $e_{i j}{ }^{\prime} s$ is distributed $N(0, R)$, where $R$ is some spatial covariance matrix. To analyze data using this model using PROC MIXED, the following input statements are minimally required:

DATA a;

INPUT fix_eff rand_eff row col y;

In describing program statements, we will refer to words that are mandatory verbatim in the program using capital letters and words that are mandatory but the specific word is user's choice using lower case. The variables "fix eff" and "rand eff" name the fixed and random factors in the model, "row" and "col" locāte the observation in space, and "y" is the observed response. The number and specific names of the fixed and random factors will depend on the particular data set. Some data sets may have none, e.g. if estimating the semivariogram is the only objective (see section 3 ). Others may have only a fixed effect, e.g. treatment. Others may have several fixed and random effects, e.g. factorial treatments designs (factor A, B, etc.), and blocks, locations, etc. ALL data sets must have a "col" and "row" variable, corresponding, for example, to the longitudinal or east-west and the latitudinal, or north-south location of the observation, respectively.

The following is the basic SAS program. Variables in italics are not mandatory, but we have found them to be useful options.

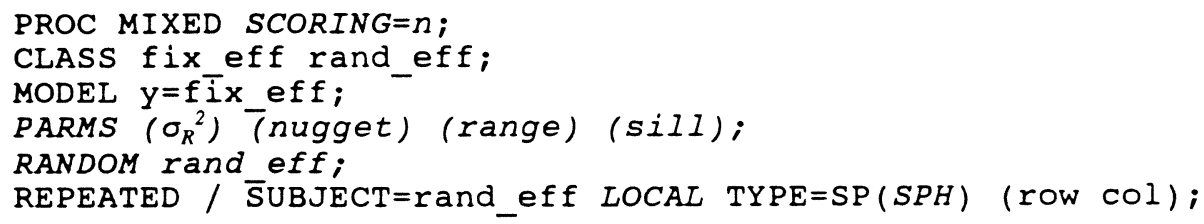

The SCORING option forces the REML algorithm to use a scoring procedure at least $n$ times per iteration. We have found this option to be very helpful in obtaining convergence to reasonable solutions for the range and sill. The values in parenthesis in the PARMS statement are initial numeric values for the variance and covariance parameters. Typically, the nugget is assumed to 
be zero, so the nugget option often will not be used in the PARMS statement. $\sigma_{R}^{2}$ will only be specified is one wishes to include the random effect in the model (which, note, is included in a separate RANDOM statement, not in the MODEL statement a la SAS-GLM). Our experience is that it is essential to specify initial estimates of the range and sill; PROC MIXED's default initial values frequently lead to grossly unreasonable estimates of the sill and range.

REPEATED specifies the structure of the covariance matrix, $R$, of the e vector. If there is a random effect in the model, use SUBJECT=rand eff; otherwise use SUBJECT=INTERCEPT. LOCAL is used if the nugget is assumed to be non-zero. TYPE specifies the covariance (or semivariance) model to be estimated. The example above is for the spherical semivariance model. Other options include EXP (exponential), GAU (gaussian), and LIN (linear). Consult the SAS manual for other options.

\section{EXAMPLE 1 - NO TREATMENT EFFECTS, NUGGET ZERO}

In this example, we present the SAS statements required to estimate the sill and range of a rectangular array of spatially correlated data. The data are given in Table 1. Please note that only the location (LAT and LNG, $i . e$. "row" and "col") and response (X) variables from Table 1 are used in this example. The model is

$$
Y_{i}=\mu+e_{i} \text {, where e is distributed } N(0, R) \text {. }
$$

The program:

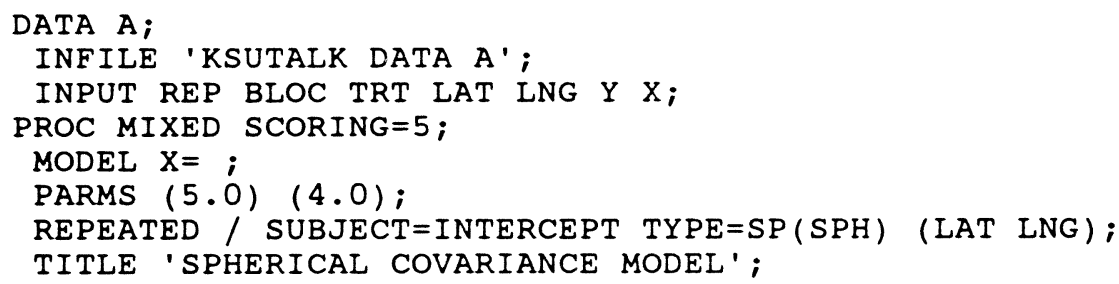

The PARMS statement contains initial estimates of the range and sill. No value for $\sigma_{R}{ }^{2}$ is included (since there is no RANDOM statement) and no value for nugget is included (i.e. we assume it is zero). Selected output:

SPHERICAL COVARIANCE MODEL

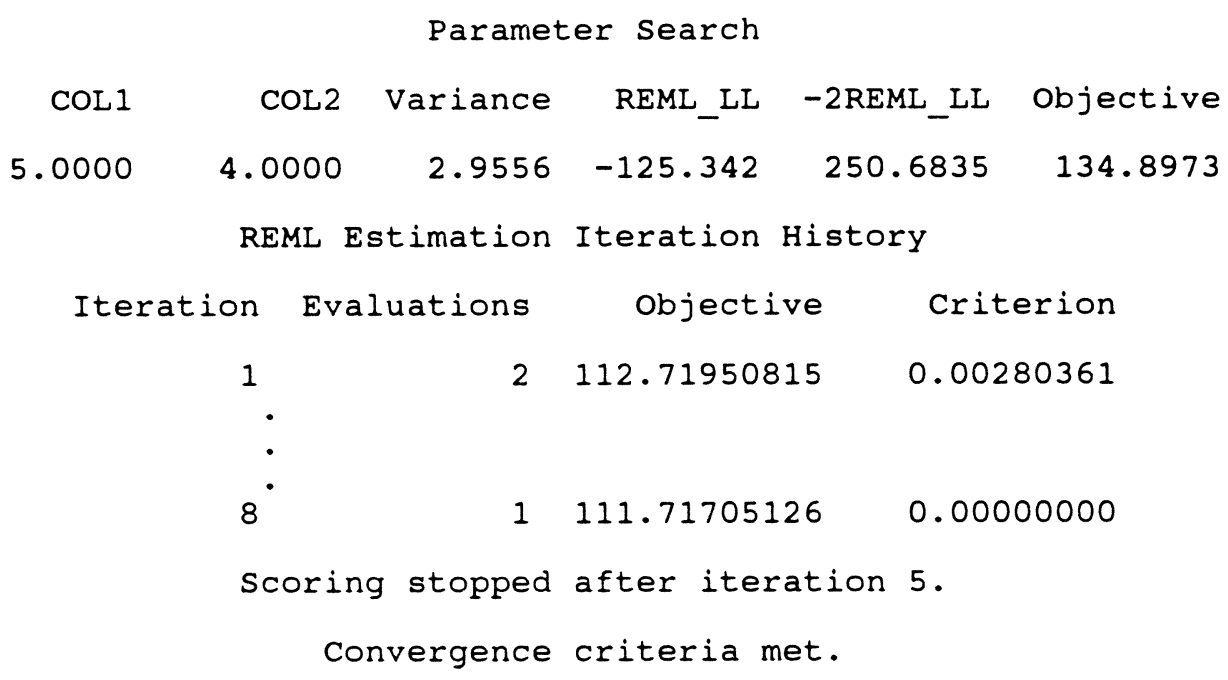


Covariance Parameter Estimates (REML)

$\begin{array}{lrrrrr}\text { Cov Parm } & \text { Ratio } & \text { Estimate } & \text { Std Error } & \mathrm{Z} & \operatorname{Pr}>|\mathrm{z}| \\ \text { DIAG SP(SPH) } & 2.71198105 & 8.84278813 & 2.77131363 & 3.19 & 0.0014 \\ \text { Residual } & 1.0000000 & 3.26063787 & 0.65576061 & 4.97 & 0.0000\end{array}$

Model Fitting Information for $\mathrm{X}$

$\begin{array}{lr}\text { Description } & \text { Value } \\ \text { Observations } & 64.0000 \\ \text { Variance Estimate } & 3.2606 \\ \text { Standard Deviation Estimate } & 1.8057 \\ \text { REML Log Likelihood } & -113.752 \\ \text { Akaike's Information Criterion } & -115.752 \\ \text { Schwarz's Bayesian Criterion } & -117.895 \\ \text {-2 REML Log Likelihood } & 227.5033 \\ \text { PARMS Model LRT Chi-Square } & 23.1802 \\ \text { PARMS Model LRT DF } & 1.0000 \\ \text { PARMS Model LRT P-Value } & 0.0000\end{array}$

The REML iteration history tracks the progress of the sill and range estimates. The important line is "convergence criteria met." The range and sill estimates are, respectively, 2.712 and 3.261 (rounded to 3 decimal places). They are given under the "ratio" for DIAG SP(SPH), and the "estimate" for "residual," respectively. This output was produced by Version 6.07 of SAS. Later versions have the actual estimate of the range under the "estimate" column; thus a Version 6.08 PROC MIXED output would have 0.832 and 1.000, respectively in the "ratio" column and 2.712 and 3.261 respectively in the "estimate" column.

The model fitting information can be useful in comparing plausible models. The REML log likelihood, and two related criteria, Akaike's Information and Schwarz's Bayesian, which are adjusted for various model characteristics, can be used for likelihood ratio tests when comparing models which are subsets of one another, or simply interpreted as "the higher, the better" for different models with the same number of parameters. These data were also fit using the exponential, gaussian, and linear semivariance models. The linear produced a warning "Scoring did not stop. stopped because of infinite likelihood," which is typical - the linear semivariance model works poorly with the mixed model and REML. For the others, the model fitting output was

EXPONENTIAL COVARIANCE MODEL

REPEATED / SUBJECT=INTERCEPT TYPE=SP (EXP) (LAT LNG);

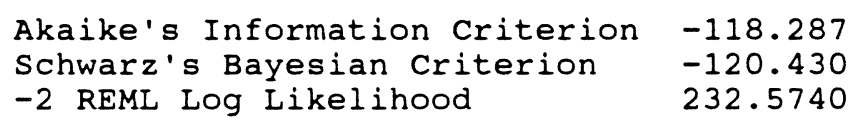

GAUSSIAN COVARIANCE MODEL

REPEATED / SUBJECT=INTERCEPT TYPE=SP (GAU) (LAT LNG);

$\begin{array}{ll}\text { Akaike's Information Criterion } & -118.056 \\ \text { Schwarz's Bayesian Criterion } & -120.199 \\ -2 \text { REML Log Likelihood } & 232.1112\end{array}$ 
Thus, the spherical model would be preferred, because the Akaike and Schwarz criteria are higher and the -2 REML Log Likelihood is lower.

The "PARMS model LRT" (likelihood ratio test) tests $\mathrm{H}_{0}$ : range=0 if NO parms option is used, but it test the hypothesis that the difference between the initial value and the estimated value is zero when the PARMS statement is used. This is not a particularly useful test.

\section{EXAMPLE 2 - COMPLETELY RANDOM DESIGN WITH CORRELATED ERRORS}

The second example contains 64 observations on 16 treatments, laid out in an $8 \times 8$ array of field plots. Data appear in Table 1. The 64 observations were subdivided into four squares, corresponding to replications of a 4 x 4 lattice design, but, for now, we will analyze them according to the model

$$
Y_{i j}=\mu+\tau_{i}+e_{i j} \text {, where e is distributed } N(0, R) \text {. }
$$

The SAS program:

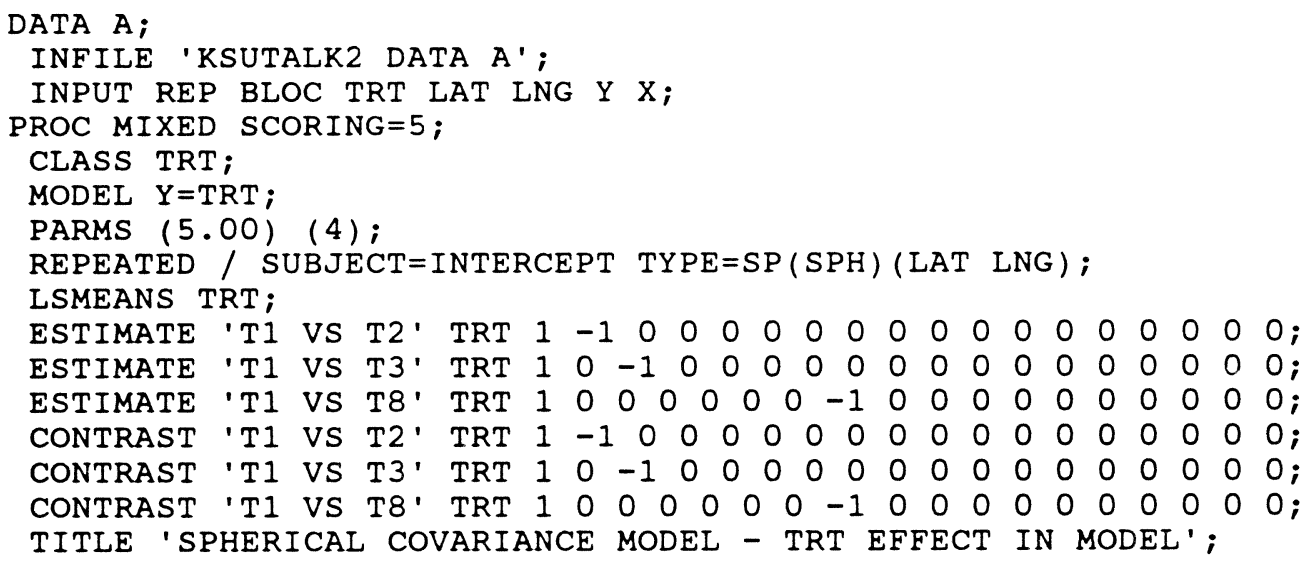

Selected output:

SPHERICAL COVARIANCE MODEL - TRT EFFECT IN MODEL

Covariance Parameter Estimates (REML)

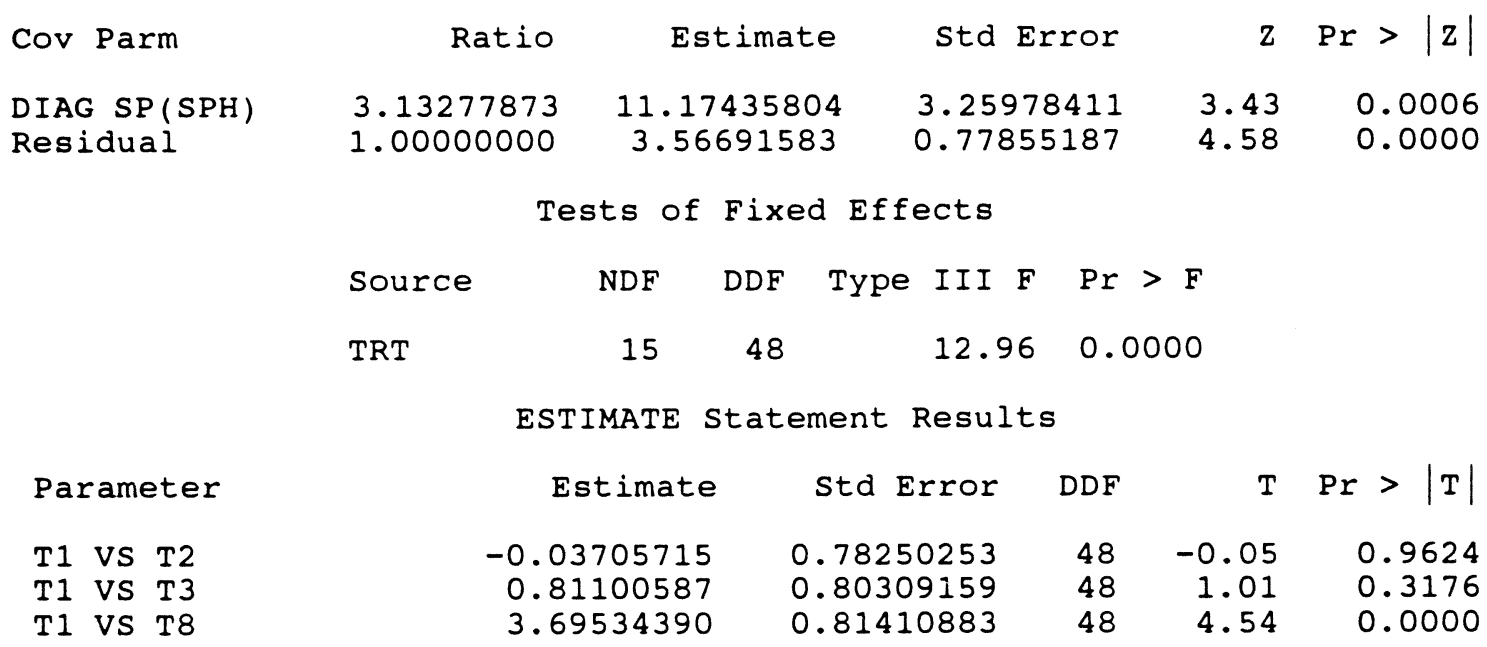


CONTRAST Statement Results

$\begin{array}{lrrrr}\text { Source } & \text { NDF } & \text { DDF } & \text { Pr } & \text { Pr F } \\ \text { T1 VS T2 } & 1 & 48 & 0.00 & 0.9624 \\ \text { T1 VS T3 } & 1 & 48 & 1.02 & 0.3176 \\ \text { T1 VS T8 } & 1 & 48 & 20.60 & 0.0000\end{array}$

Least Squares Means

Level

TRT 1

TRT 2

TRT 3
LSMEAN

12.49765196
12.53470911
11.68664609

std Error

DDF

0.74954746

0.75986106

0.76719779

$\begin{array}{ll}48 & 16.67 \\ 48 & 16.50 \\ 48 & 15.23\end{array}$

$\mathrm{T} \operatorname{Pr}>|\mathrm{T}|$

The data are actually the same as example 1 except that treatment effects were added according to the lattice design. The estimates of range and sill are 3.133 and 3.567 , different, but not substantially so, from the previous example. Note that PROC MIXED only gives F-values rather than a full ANOVA (sums of squares and mean squares do not have any conventionally useful meaning in mixed models). Also the standard errors for least squares means and differences are not the same. Although the number of observations per treatment are equal, the observations lie at different points on the local gradients resulting from the spatial correlation and at different average distances from one another. Assuming the spatial correlation is accurately estimated, the variability estimates for means and differences are thus more realistic.

These data could alternatively be analyzed using conventional ANOVA models. In particular, the traditional RCBD model or the lattice model could be evaluated. Selected results are as follows:

CLASS REP TRT;

MODEL Y=TRT;

RANDOM REP;

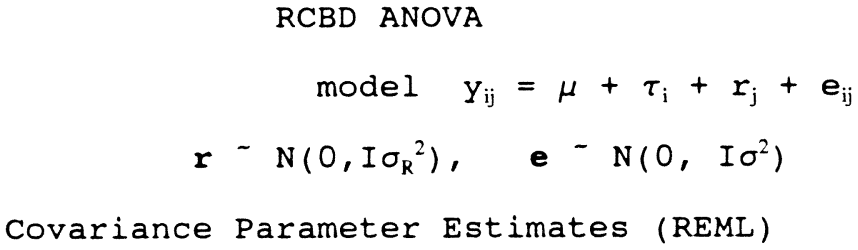

RCBD ANOVA

model $Y_{i j}=\mu+\tau_{i}+r_{j}+e_{i j}$$$
r^{-N}\left(0, I \sigma_{R}^{2}\right), \quad e^{-N\left(0, I \sigma^{2}\right)}
$$

Covariance Parameter Estimates (REML)

$\begin{array}{lrrrrr}\text { Cov Parm } & \text { Ratio } & \text { Estimate } & \text { Std Error } & \mathrm{z} & \mathrm{Pr}>|\mathrm{z}| \\ & & & & \\ \text { REP } & 0.00000000 & 0.00000000 & & \text {. } & \\ \text { Residual } & 1.00000000 & 3.05074506 & 0.6227307 \dot{3} & 4.90 & 0.0000\end{array}$

\section{LATTICE ANOVA}

CLASS REP BLOC TRT; MODEL $Y=$ TRT;

* RANDOM REP BLOC (REP); RANDOM BLOC;

Covariance Parameter Estimates (REML)

$\begin{array}{lrrrrr}\text { Cov Parm } & \text { Ratio } & \text { Estimate } & \text { Std Error } & \mathrm{Z} & \operatorname{Pr}>|\mathrm{z}| \\ \text { BLOC } & 0.73832005 & 1.31435334 & 0.70964068 & 1.85 & 0.0640 \\ \text { Residual } & 1.00000000 & 1.78019457 & 0.44073910 & 4.04 & 0.0001\end{array}$


SPHERICAL COVARIANCE MODEL - TRT EFFECT IN MODEL

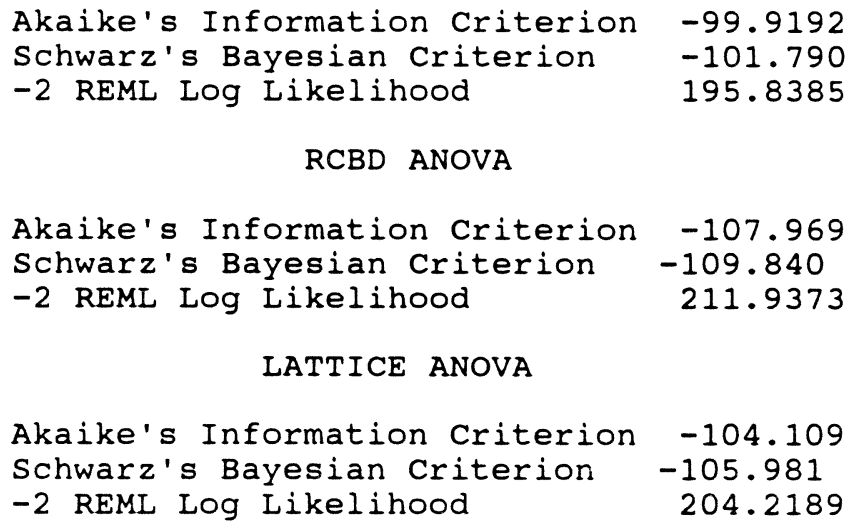

The model fitting criteria indicate that the RCBD model is inferior to the alternatives. The Lattice model is an improvement over the RCBD, but is not as good as the spatial covariance model. This result is common in the analysis of field data (see also stroup, Baenziger, and Mulitze, 1994). Complete block designs should be avoided when spatial variability is suspected. Incomplete block designs are often only partial fixes. We now turn our attention to some pitfalis we have encountered using PROC MIXED to analyze data with spatial variability.

\section{HOW TO USE PROC MIXED IN DESIGNED EXPERIMENTS}

In using PROC MIXED it is important to realize that the definitions of parameters has changed between versions. For example, in version 6.07 the parameter DIAG SP(SPH) estimates the range times the sill, and consequentially the ratio of the DIAG SP(SPH) to the residual estimates the range. In version 6.08 the parameter estimate of DIAG SP(SPH) is itself the estimate of the range. When assuming a spatial structure, say spherical, without a nugget effect only one parameter, the range, will effect the value of the log likelihood. Since SAS uses an iterative procedure, it is important to grid the parameter space for initial evaluations of the likelihood function so that local minimums can be identified. A typical plot of the range against the -2 REML log likelihood looks like figure 3 . If the range were assumed larger than six then the procedure would converge to a local minimum.

Often the procedure will not converge. If this is the case using SCORING $=10$ will often help. Another practice which should be followed when using PROC MIXED in spatially correlated models is to graph the empirical semivariogram with the modeled semivariogram from PROC MIXED. A simple procedure to do this is to use the fixed effects derived from PROC MIXED and calculate the residuals. Use these residuals in a geostatistical package, such as GEOEAS, and have that package automatically obtain the empirical semivariogram and then input the parameters of the modeled semivariogram from PROC MIXED. A caution is noted here: sometimes GEOEAS will not use the larger lag distances and hence the resulting graph may be misleading. In figure 4 the maximum lag distance was 5 and it looks as if PROC MIXED has underestimated the sill. However, if all the lags are used, the modeled semivariogram looks much better as in figure 5 .

PROC MIXED can be used to help determine which spatial model is appropriate for a set of data. This can be done by first assuming a particular spatial model, say spherical, and obtaining the model fitting 
criteria (Akaike's, Schwarz's, and -2 REML LL), then repeating the process for several other models, say gaussian and exponential. The fitted models can be graphed and the fitting criteria compared. For example, in $f$ igure 6 the graph indicates that the spherical fitted model looks better than either the exponential or gaussian. However, even though the sill seems a little too high for the spherical, the gaussian clearly underestimates the sill and the exponential overestimates it.

Finally, the likelihood is not appropriately calculated for some starting values in the gaussian model. In figure 7 , at large ranges, the value for -2 REML LL will abruptly change between a reasonable value (around 1200 ) and an unreasonable large number (say 1.789E308). Hence there are a number of local minimums as seen in the gaussian graph in figure 7 . For this experimental data set, the three different models used provided the following statistics (Table 2):

Table 2. Statistics associated with one simulation run (\#1) corresponding to Figure 7 .

\begin{tabular}{|c|c|c|c|c|c||}
\hline Model & Range & Sill & Akaike's & Schwarz's & -2 REML LI \\
\hline \hline Spherical & 2.916 & 5.161 & -128.22 & -130.36 & 252.44 \\
\hline Exponential & 1.895 & 6.054 & -129.25 & -131.39 & 254.49 \\
\hline Gaussian & 1.005 & 4.530 & -131.22 & -133.36 & 255.44 \\
\hline
\end{tabular}

These three models are graphed in figure 8 , and as one can see the models are all very similar. Again it is important to look at the graphs as well as the fitting criteria since the best fit model may be totally inadequate.

A simple simulation study was run using 100 simulations of 64 spatially correlated observations each in an 8 by 8 grid. For each run the original spatially correlated data had treatment effects added to the observations for the 16 treatments. The treatment effects were $13,13,14,14,15,15$, $16,16,16,16,17,17,18,18,19$, and 19. The spatial model used was spherical with no nugget effect, a range of 3.50 and a sill of 4.00 . First we tried to determine if PROC MIXED would be able to correctly handle the treatment effects. The results indicted that PROC MIXED would estimate the fixed effects very accurately in that the average of the simulation treatment effects were very close to the true treatment effect and had little variability from run to run. As an example the true treatment effect for treatments 1 and 2 were both 13. The average for the 100 simulation effects given by PROC MIXED were 12.94 and 13.03 respectively with standard deviations of 0.77 and 0.76 . The results of the simulation indicated that PROC MIXED does a fairly good job of estimating the sill as seen in Table 3. However, PROC MIXED also tends to underestimate the range, although with only 100 simulations the underestimation is not statistically significant $(p>.05)$. The true spatial structure was spherical and the model assumed by PROC MIXED was spherical as well. The results are: 
Table 3. Comparison of Simulation Data 100 Simulations of 64 Observations

\begin{tabular}{|c|c|c|c|c|c|}
\hline & parameter & mean & maximum & minimum & std dev \\
\hline \multirow{2}{*}{$\begin{array}{c}\text { No treatment } \\
\text { Effect }\end{array}$} & range & 3.08 & 5.30 & 1.55 & 0.63 \\
\hline & sill & 4.03 & 7.35 & 2.09 & 0.98 \\
\hline \multirow{2}{*}{$\begin{array}{c}\text { Treatment } \\
\text { Effect }\end{array}$} & range & 3.09 & 6.26 & 1.68 & 0.75 \\
\hline & sill & 3.99 & 8.21 & 1.94 & 1.07 \\
\hline \multirow[t]{2}{*}{ Difference } & range & $-0.01 *$ & 1.55 & -2.60 & 0.50 \\
\hline & sill & $0.05 *$ & 2.64 & -3.56 & 0.72 \\
\hline
\end{tabular}

* not significant $(p>.05)$

One common (Cressie, 1991) method of removing "drift" of fixed effects from spatially correlated data is by the use of median polish. The original data are "polished" and the residuals from the polished data are then assumed to be free of drift and can then be subjected to the usual geostatistical estimation procedures. Median polish is preferred to mean polishing in that it is suspected that mean polishing also polishes out some of the spatial correlation. Thus the simulated data were polished to remove drift (here a linear drift) and drift was removed by PROC MIXED. These were compared to the original data before the drift was added in Table 4 . Both the range and the sill are significantly $(\mathrm{p}<.05)$ for the polished data.

Table 4. Simulated Results for Polished Data

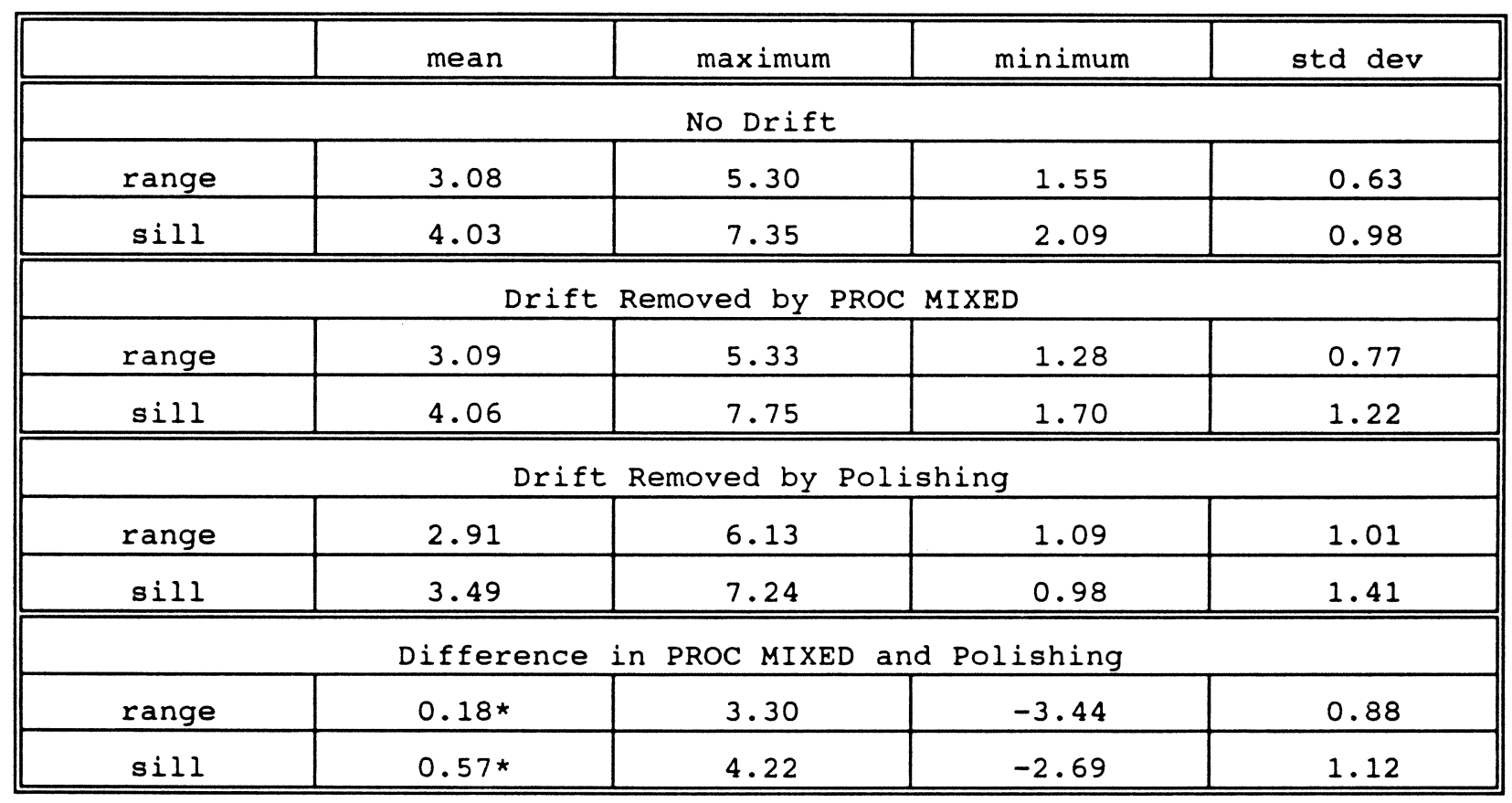

* both range and sill are significantly smaller $(\mathrm{p}<.05)$ for polished data 
To determine how well the exponential and gaussian models fit the spherical data PROC MIXED was used assuming those spatial structures. Since the data were simulated using a spherical structure we would not expect the exponential or gaussian models to estimate the range or sill as well. These results (Table 5) indicate that the average range (sill) is different with the spherical (exponential) model being the largest and the gaussian (gaussian) being the smallest. Note how the gaussian underestimates the range and the exponential overestimates the sill. Actual values should be close to the simulation parameters of the range $=3.50$ and the $8 i 11=4.00$.

Table 5. Simulation Results for Spherical Exponential and Gaussian Models

\begin{tabular}{|c|c|c|c|c|}
\hline & mean & maximum & minimum & std dev \\
\hline \multicolumn{5}{|c|}{ Spherical } \\
\hline range & 3.08 & 5.30 & 1.55 & 0.63 \\
\hline sill & 4.03 & 7.35 & 2.09 & 0.98 \\
\hline \multicolumn{5}{|c|}{ Exponential } \\
\hline range & 2.29 & 8.14 & 0.59 & 1.41 \\
\hline sill & 5.37 & 16.08 & 2.12 & 2.75 \\
\hline \multicolumn{5}{|c|}{ Gaussian } \\
\hline range & 1.02 & 1.29 & 0.76 & 0.09 \\
\hline sill & 3.49 & 5.22 & 2.02 & 0.75 \\
\hline
\end{tabular}

To determine if PROC MIXED had a preference for one spatial structure over another we simulated 100 exponential data sets each with 64 observations as well as 100 gaussian data sets. All data sets were structured as in the previous simulation with treatment effects, 8 by 8 grid and same nugget, range and sill. However, the spatial structure was exponential or gaussian rather than spherical. Combining the two simulation runs we now have a data set which consists of 100 runs of each of spherical, exponential and gaussian. PROC MIXED was used to compute Akaike's and Schwarz's criteria and -2 REML LL. Using these fitting criteria the "best" of either spherical, exponential, or gaussian models was chosen. These results (Table 6 ) indicated that the model chosen was generally correct. If the data were actually exponential, the exponential model fit best over $60 \%$ of the time with the other two models about splitting the remaining data sets. If the data were gaussian the gaussian model always fit best. This seems to be because of the s-shaped nature of the gaussian model which neither the spherical nor the exponential can adequately represent. The spherical model was correctly identified over 758 of the time when the original data were spherical. 
Table 6. Simulation Result for Spherical Exponential and Gaussian Data

\begin{tabular}{||c||c|c|c||}
\hline \multicolumn{1}{|c|}{} & \multicolumn{3}{|c|}{ Model Chosen } \\
\hline Data structure & Spherical & Exponential & Gaussian \\
\hline Spherical & 77 & 12 & 11 \\
\hline Exponential & 21 & 64 & 15 \\
\hline Gaussian & 0 & 0 & 100 \\
\hline
\end{tabular}

In conclusion, we would recommend that the researcher always use SCORING=10 so that many of the problems of failing to converge will be alleviated. Secondly, we would grid the parameter space fairly densely. Look at the map of the gridded values to see if local minimums exist. Try several models including the spherical, exponential, and gaussian. Also try a model with and without the nugget effect. Remove "drift" if necessary and compare the results when drift was assumed to be absent. Finally, compare the final model with the empirical semivariogram. It will take a great amount of time to use PROC MIXED with spatially correlated data effectively, but the results are worth the effort.

In the future, we would like to see SAS implement nested structures and anisotropic models in PROC MIXED. A test for isotropy would be extremely helpful and allow a more effective way of choosing between an isotropic or anisotropic model. The scoring problem needs to be rectified so that SCORING=10 would not have to be included every time. Although we realize that there is a great tendency to misuse multiple comparisons, it would be extremely convenient if a multiple comparison were easily available in PROC MIXED. 


\section{REFERENCES}

Cressie, N. 1991. Statistics for Spatial Data. John Wiley: New York

Harville, D.A. 1976. Extension of the Gauss-Markov Theorem to include the estimation of random effects. Ann. Statist. 4:384-395.

Harville, D.A. 1977. Maximum likelihood approaches to variance component estimation and to related problems. J. Amer. Statist. Assoc. 72:320-340.

Henderson, C.R. 1975. Best linear unbiased estimation and prediction under a selection model. Biometrics $31: 19-28$.

Jeske, D.R. and D.A. Harville. 1988. Prediction-interval and (fixed-effects) confidence-interval prediction for mixed linear models. Commun. Statist.Theory Meth. 17(4): 1053-1087.

Journel, A.G., and C. Huijbregts. 1978. Mining geostatistics. Academic Press. London.

Mclean, R.A., W.L. Sanders, and W.W. Stroup. 1991. A unified approach to mixed linear models. Amer. Statistician. 45:54-63.

SAS Institute. 1992. SAS technical report P-229, SAS/STAT software: changes and enhancements, release 6.07. SAS Institute Inc., Cary, NC.

Stroup, W.W., P.S. Baenziger, and D.K. Mulitze. 1994. Comparison to methods to account for spatial variation in wheat yield trials. Crop science. in press - to appear in January-February, 1994 issue.

Zimmerman, D.L., and D.A. Harville. 1991. A random field approach to the analysis of field plot experiments and other spatial experiments. Biometrics $47: 223-240$. 
Types of Variability Among Experimental Units

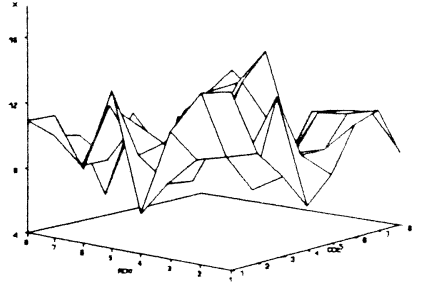

Case 1

Non-systematic variation

CRD appropr iate.

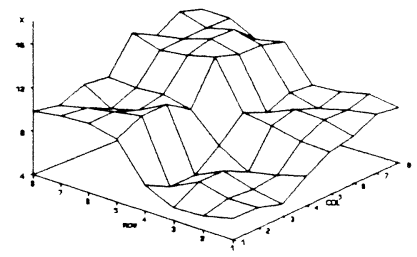

Case 2 .

Homogeneous subsets RCBD appropr iate

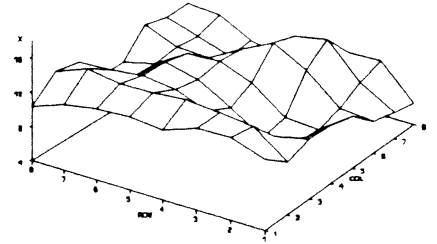

Case 3

Spatial variability Proper design not obvious.

Figure 1

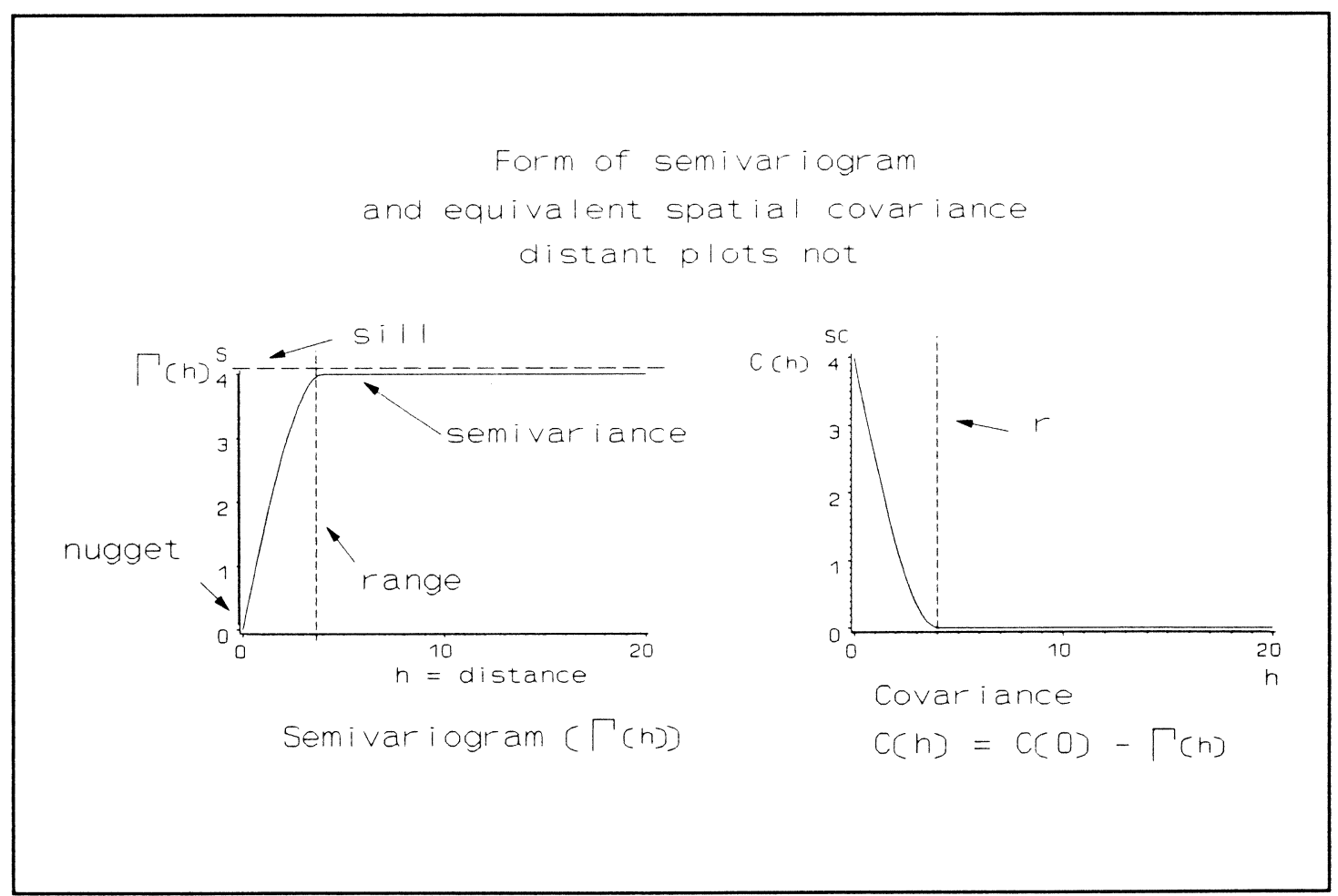

Figure 2 


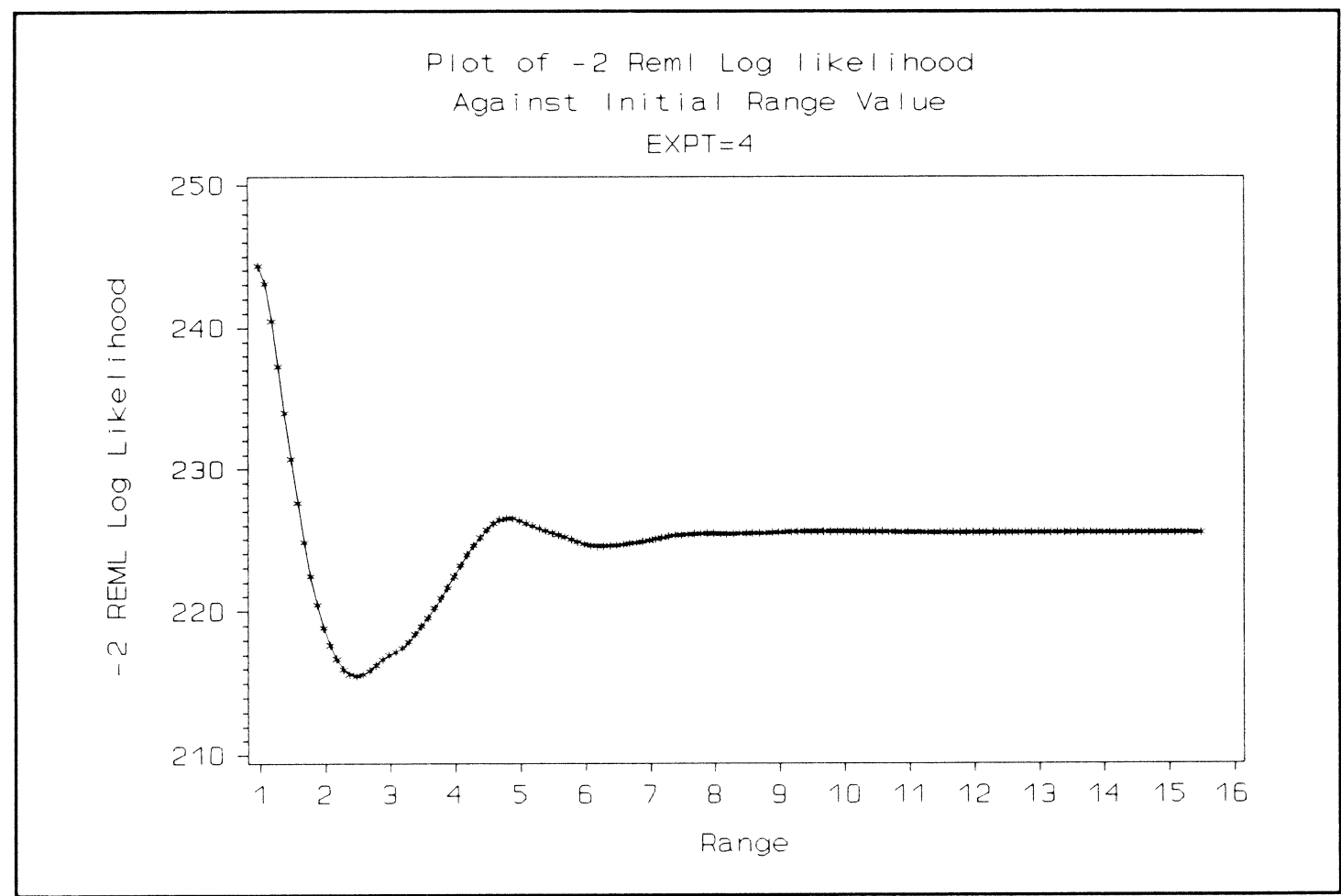

Figure 3

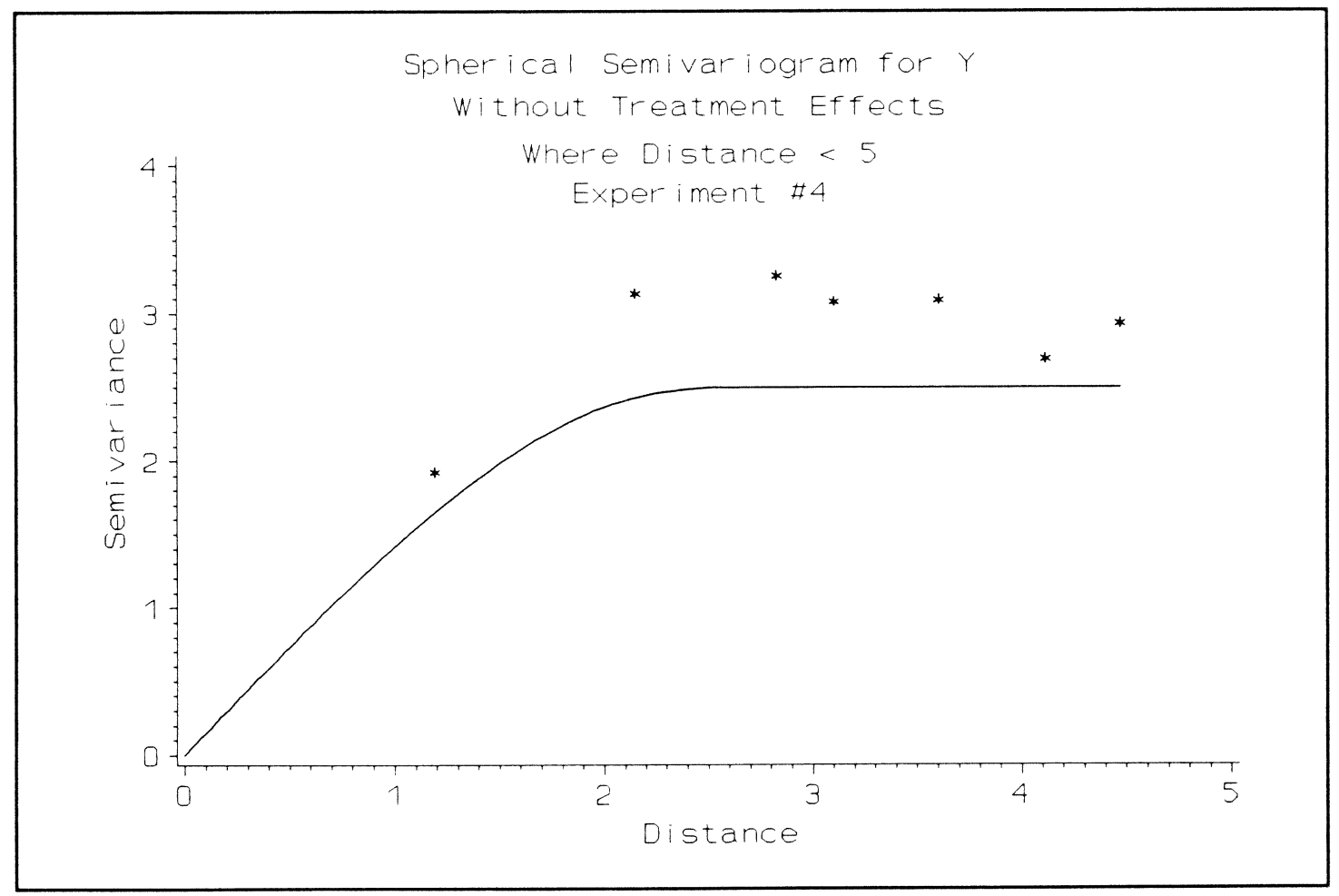

Figure 4 


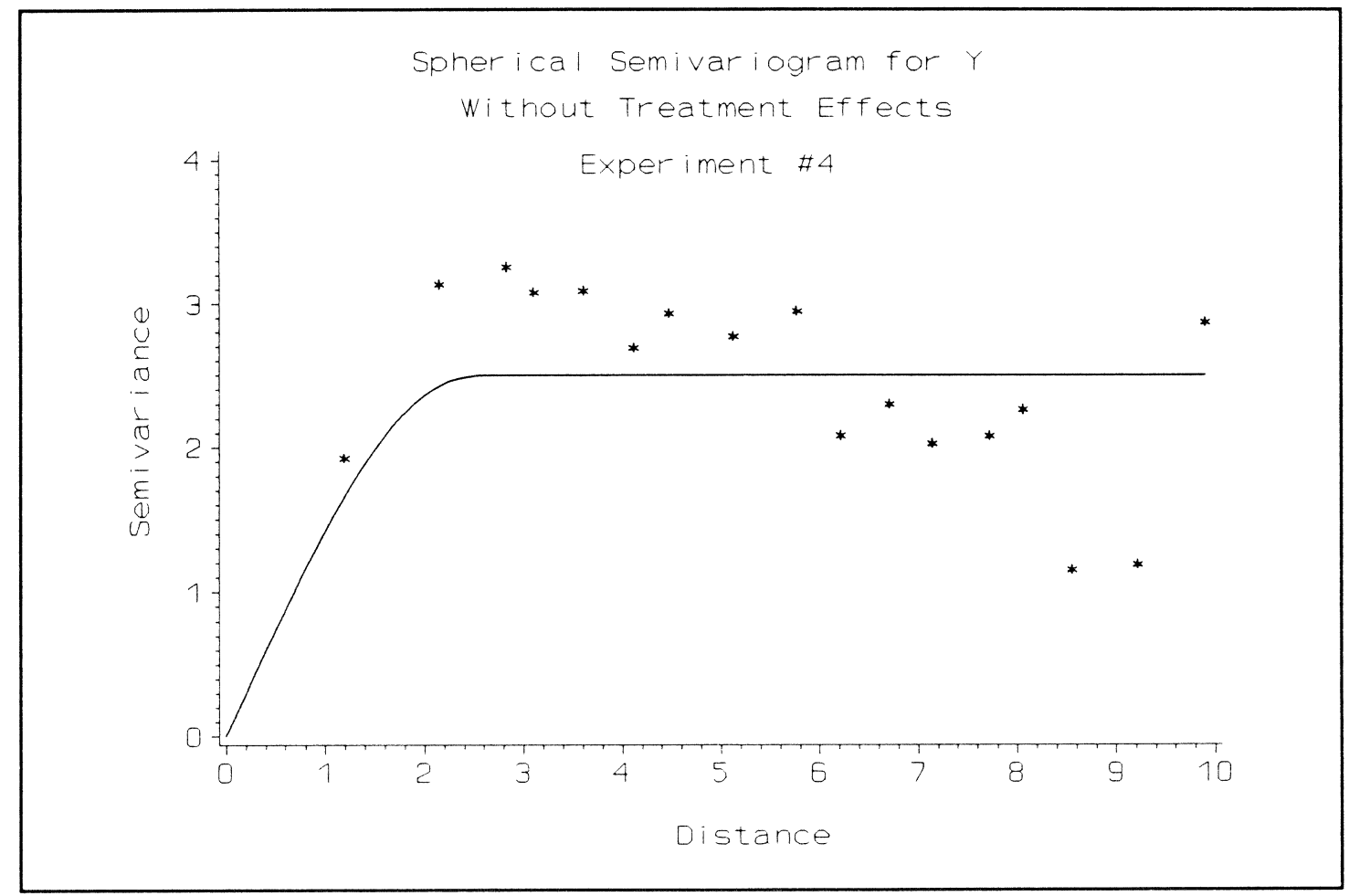

Figure 5

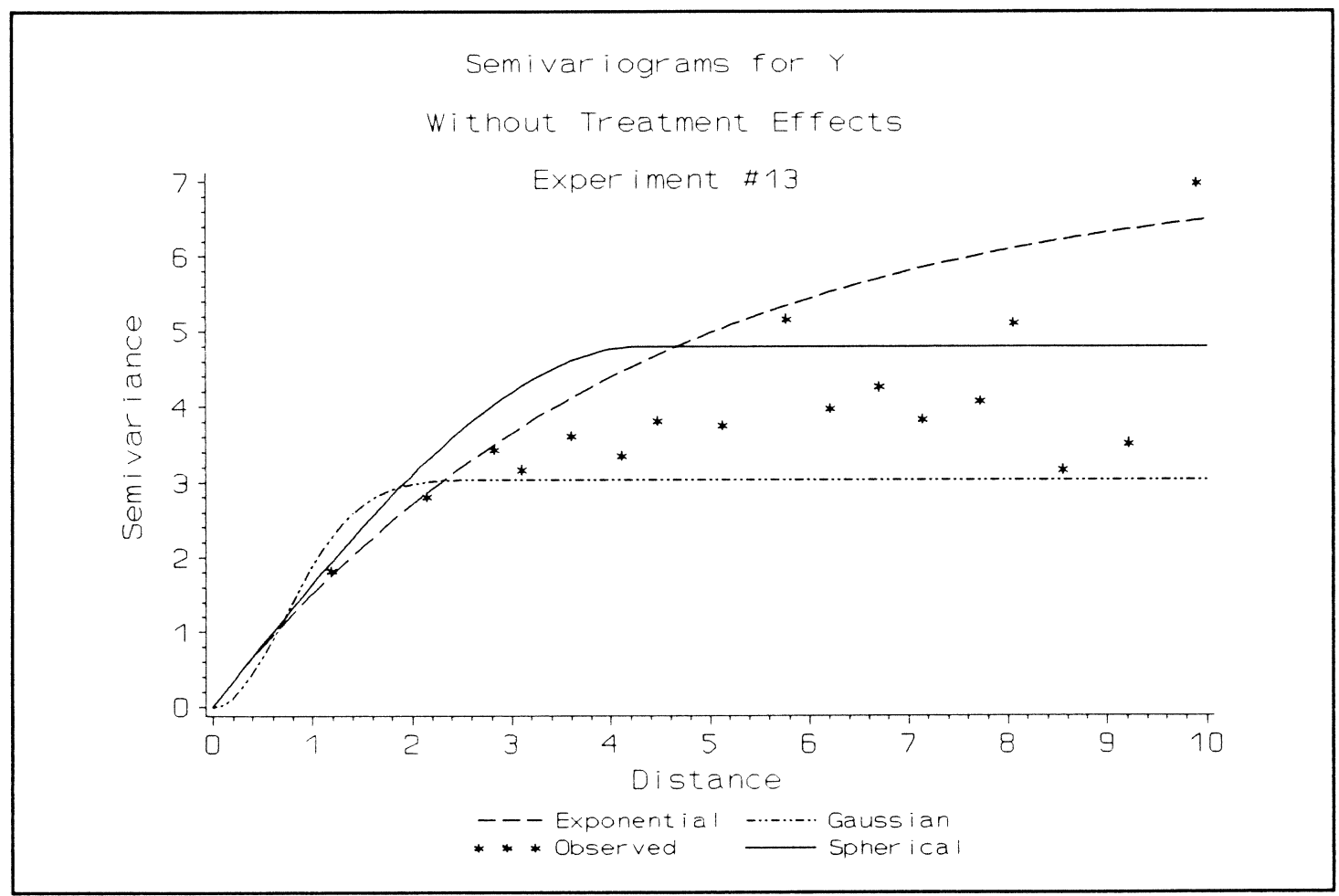

Figure 6 


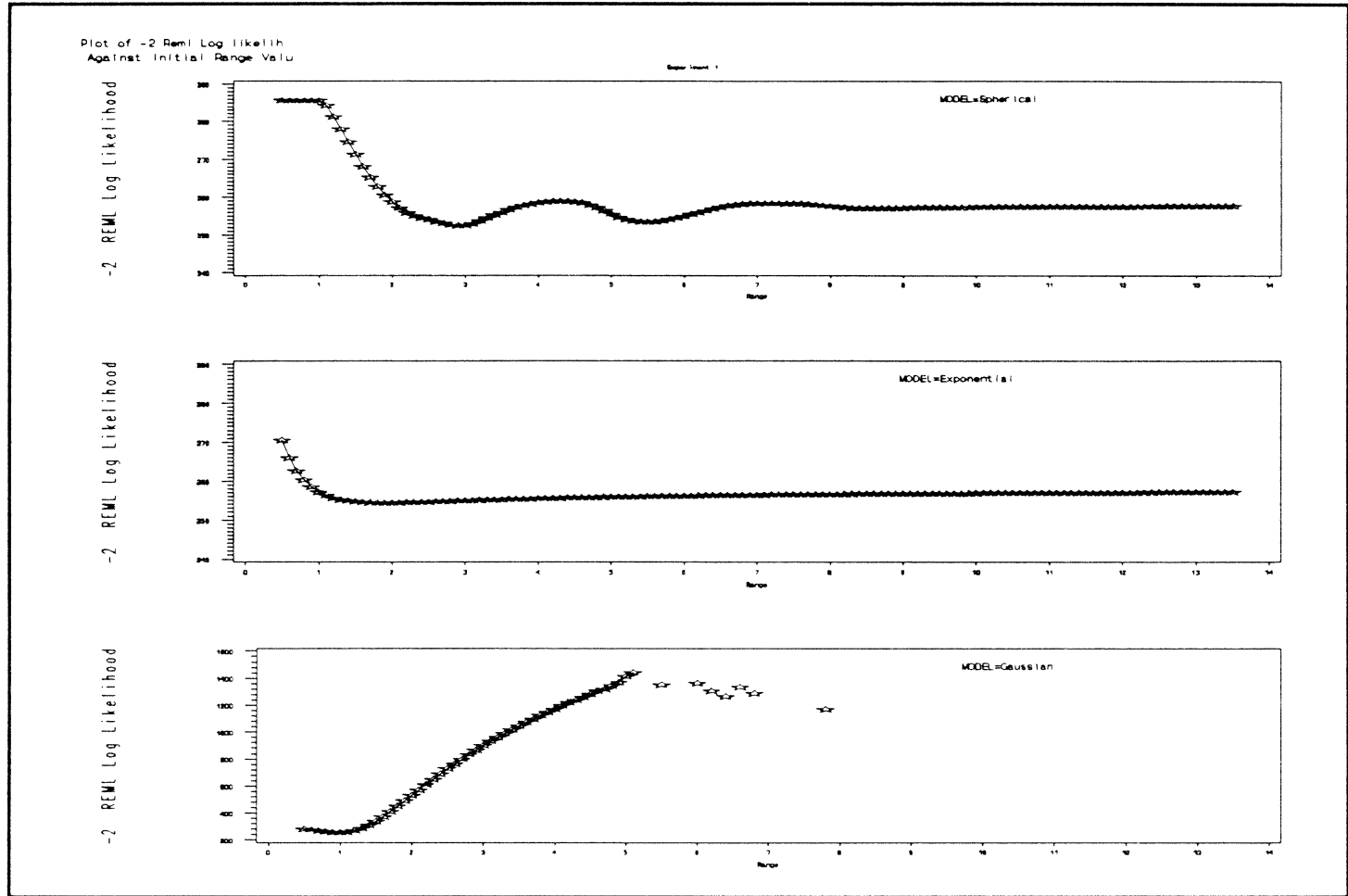

Figure 7

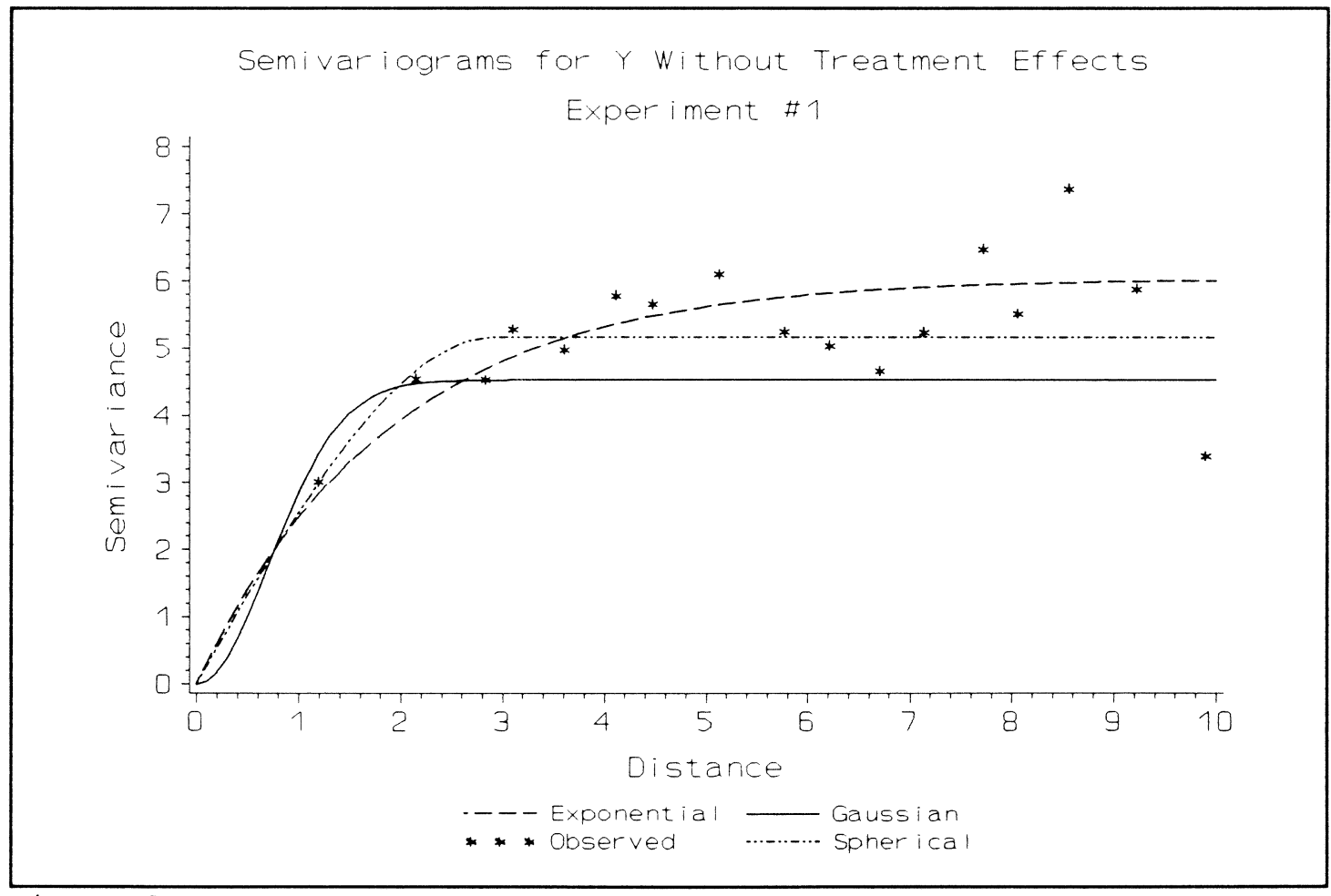

Figure 8 
Table 1. Data set used in examples 1 and $2 . x$ is response variable used in example $1 . Y$ is response variable in example 2 .

\begin{tabular}{|c|c|c|c|c|c|c|c|}
\hline OBS & REP & BLOC & $\mathrm{TRT}$ & LAT & LNG & $Y$ & $\mathrm{x}$ \\
\hline 1 & 1 & 4 & 14 & 1 & 1 & 8.5411 & 10.5411 \\
\hline 2 & 1 & 4 & 16 & 1 & 2 & 5.5806 & 8.5806 \\
\hline 3 & 1 & 2 & 7 & 1 & 3 & 11.2790 & 11.2790 \\
\hline 4 & 1 & 2 & 6 & 1 & 4 & 13.4344 & 12.4344 \\
\hline 5 & 1 & 4 & 13 & 2 & 1 & 8.3416 & 10.3416 \\
\hline 6 & 1 & 4 & 15 & 2 & 2 & 8.3103 & 11.3103 \\
\hline 7 & 1 & 2 & 8 & 2 & 3 & 9.0282 & 9.0282 \\
\hline 8 & 1 & 2 & 5 & 2 & 4 & 10.7985 & 9.7985 \\
\hline 9 & 1 & 3 & 11 & 3 & 1 & 9.4939 & 10.4939 \\
\hline 10 & 1 & 3 & 12 & 3 & 2 & 10.2576 & 11.2576 \\
\hline 11 & 1 & 1 & 2 & 3 & 3 & 10.3720 & 7.3720 \\
\hline 12 & 1 & 1 & 3 & 3 & 4 & 8.0833 & 6.0833 \\
\hline 13 & 1 & 3 & 10 & 4 & 1 & 9.8869 & 9.8869 \\
\hline 14 & 1 & 3 & 9 & 4 & 2 & 8.2849 & 8.2849 \\
\hline 15 & 1 & 1 & 4 & 4 & 3 & 9.2836 & 7.2836 \\
\hline 16 & $\overline{1}$ & 1 & 1 & 4 & 4 & 11.0018 & 8.0018 \\
\hline 17 & 2 & 7 & 15 & 5 & 1 & 7.3349 & 10.3349 \\
\hline 18 & 2 & 7 & 3 & 5 & 2 & 11.9135 & 9.9135 \\
\hline 19 & 2 & 6 & 10 & 5 & 3 & 8.1662 & 8.1662 \\
\hline 20 & 2 & 6 & 2 & 5 & 4 & 13.7679 & 10.7679 \\
\hline 21 & 2 & 7 & 11 & 6 & 1 & 11.1580 & 12.1580 \\
\hline 22 & 2 & 7 & 7 & 6 & 2 & 11.0230 & 11.0230 \\
\hline 23 & 2 & 6 & 14 & 6 & 3 & 7.2912 & 9.2912 \\
\hline 24 & 2 & 6 & 6 & 6 & 4 & 10.1392 & 9.1392 \\
\hline 25 & 2 & 5 & 5 & 7 & 1 & 14.1097 & 13.1097 \\
\hline 26 & 2 & 5 & 13 & 7 & 2 & 8.0121 & 10.0121 \\
\hline 27 & 2 & 8 & 12 & 7 & 3 & 7.2482 & 8.2482 \\
\hline 28 & 2 & 8 & 16 & 7 & 4 & 4.3975 & 7.3975 \\
\hline 29 & 2 & 5 & 9 & 8 & 1 & 11.0226 & 11.0226 \\
\hline 30 & 2 & 5 & 1 & 8 & 2 & 13.7690 & 10.7690 \\
\hline 31 & 2 & 8 & 8 & 8 & 3 & 6.2206 & 6.2206 \\
\hline 32 & 2 & 8 & 4 & 8 & 4 & 8.5696 & 6.5696 \\
\hline 33 & 3 & 12 & 7 & 1 & 5 & 11.1944 & 11.1944 \\
\hline 34 & 3 & 12 & 13 & 1 & 6 & 5.9737 & 7.9737 \\
\hline 35 & 3 & 11 & 8 & 1 & 7 & 5.8400 & 5.8400 \\
\hline 36 & 3 & 11 & 14 & 1 & 8 & 4.9580 & 6.9580 \\
\hline 37 & 3 & 12 & 4 & 2 & 5 & 12.2561 & 10.2561 \\
\hline 38 & 3 & 12 & 10 & 2 & 6 & 9.8180 & 9.8180 \\
\hline 39 & 3 & 11 & 3 & 2 & 7 & 12.3009 & 10.3009 \\
\hline 40 & 3 & 11 & 9 & 2 & 8 & 7.4719 & 7.4719 \\
\hline 41 & 3 & 9 & 6 & 3 & 5 & 11.1148 & 10.1148 \\
\hline 42 & 3 & 9 & 1 & 3 & 6 & 12.6252 & 9.6252 \\
\hline 43 & 3 & 10 & 15 & 3 & 7 & 5.7800 & 8.7800 \\
\hline 44 & 3 & 10 & 12 & 3 & 8 & 10.2786 & 11.2786 \\
\hline 45 & 3 & 9 & 11 & 4 & 5 & 6.9548 & 7.9548 \\
\hline 46 & 3 & 9 & 16 & 4 & 6 & 3.1100 & 6.1100 \\
\hline 47 & 3 & 10 & 5 & 4 & 7 & 9.6507 & 8.6507 \\
\hline 48 & 3 & 10 & 2 & 4 & 8 & 12.2237 & 9.2237 \\
\hline 49 & 4 & 16 & 9 & 5 & 5 & 10.3129 & 10.3129 \\
\hline 50 & 4 & 16 & 4 & 5 & 6 & 9.3161 & 7.3161 \\
\hline 51 & 4 & 13 & 12 & 5 & 7 & 7.6394 & 8.6394 \\
\hline 52 & 4 & 13 & 1 & 5 & 8 & 10.8669 & 7.8669 \\
\hline
\end{tabular}


Table 1 . continued.

\begin{tabular}{rrrrrrrr} 
OBS & REP & BLOC & TRT & LAT & LNG & \multicolumn{1}{c}{ X } \\
53 & 4 & 16 & 15 & 6 & 5 & 6.0250 & 9.0250 \\
54 & 4 & 16 & 6 & 6 & 6 & 8.2483 & 7.2483 \\
55 & 4 & 13 & 14 & 6 & 7 & 8.0104 & 10.0104 \\
56 & 4 & 13 & 7 & 6 & 8 & 10.0473 & 10.0473 \\
57 & 4 & 14 & 13 & 7 & 5 & 5.0507 & 7.0507 \\
58 & 4 & 14 & 8 & 7 & 6 & 11.1225 & 11.1225 \\
59 & 4 & 15 & 3 & 7 & 7 & 14.0253 & 12.0253 \\
60 & 4 & 15 & 10 & 7 & 8 & 10.4298 & 10.4298 \\
61 & 4 & 14 & 2 & 8 & 5 & 10.3220 & 7.3220 \\
62 & 4 & 14 & 11 & 8 & 6 & 9.5104 & 10.5104 \\
63 & 4 & 15 & 5 & 8 & 7 & 13.6808 & 12.6808 \\
64 & 4 & 15 & 16 & 8 & 8 & 7.4482 & 10.4482
\end{tabular}

